\title{
Recursos Dialógicos e Seu Uso em Sala de Aula no Ensino Superior: Contribuições Construcionistas Sociais
}

\author{
Laura Vilela e Souza \\ Departamento de Psicologia da Faculdade de Filosofia, Ciências e Letras de Ribeirão Preto da Universidade \\ de São Paulo
}

* Autora para correspondência: laura@ffclrp.usp.br

\section{RESUMO}

No presente relato, compartilho a experiência de uso da ferramenta dialógica "construção do contexto conversacional" em sala de aula no ensino superior. Essa ferramenta, de inspiração construcionista social, serve para a negociação e a construção conjunta docente-estudante do programa e do formato das disciplinas universitárias. Negocia-se "como queremos estar juntos/as", "para que estaremos juntos/as" e "o que faremos juntos/as". Para tanto, apresento as perguntas que podem ser feitas para os/as estudantes nessa elaboração, bem como a estrutura de conversa necessária, além de discutir seus efeitos na corresponsabilização dos/as estudantes no processo de aprendizagem, na possibilidade de maior abertura à voz dos/as estudantes e na busca de docente e estudante por um ensino realmente significativo.

Palavras-Chave: Construção do Contexto Conversacional; Ensino Superior; Construcionismo Social.

\begin{abstract}
In this text I share the use of the social constructionist dialogical tool named "construction of the conversational context" in the classroom in higher education. This tool allows teacher and students to negotiate and construct together the syllabus and format of the university classes. It allows the negotiation about "how we want to be together", "why we will be together" and "what we will do together". I present in this report the questions that can be asked for the students in this construction and the conversation structure, also I discuss its effects on the greater responsibility of the students in the learning process, on the possibility of teacher giving voice to the students and in the search of a really meaningful teaching.
\end{abstract}

Keywords: Construction of the Conversational Context; Higher Education; Social Constructionism.

Brito (1983, p. 149) afirma ser desses professores que "se preocupam mais com as causas e razões do que com a condenação pura e simples do estudante". O autor se refere às expectativas frustradas dos/as docentes em relação a como os/ as estudantes não são mais os/as mesmos/as. Tal como Brito, convido o/a leitor/a a não se render a afirmações fatalistas e saudosistas como essa e a investir em saber quem são os/as estudantes de agora, quem eles se tornaram, e como pode ser boa e produtiva essa transformação.

Para motivá-lo/a nesse empreendimento, partilho, neste breve relato, o que sustenta tal postura docente, os recursos dela derivados e alguns exemplos de seu uso em sala de aula.
Essa postura docente se sustenta na perspectiva construcionista social que, descrita sumariamente, é uma diretriz que toma qualquer "verdade", "realidade" e "fato" como construções sociais passíveis de serem questionadas em sua obviedade, e ressignificadas via trocas humanas (GERGEN \& GERGEN, 2010). O construcionismo social tem sido a base para o questionamento de posturas cientificistas tradicionais que tomam suas verdades como incontestes e, portanto, impossíveis de serem pensadas em sua historicidade (MCNAMEE \& HOSKING, 2011). No caso da educação universitária, seria o convite para contextualizarmos as verdades sobre um bom ensino e uma boa relação professor/a-aluno/a e, por 
meio dessa contextualização, reconhecermos de que forma outras verdades podem adentrar esse cenário, sem que com isso se percam a criticidade e a qualidade do ensino.

A proposta aqui apresentada se centra na coconstrução docente-estudante do programa da disciplina, suas estratégias didáticas e formas de avaliação. A estratégia prática utilizada para essa construção conjunta é a da negociação em torno de três pontos fundamentais: "como queremos estar juntos/as", "para que estaremos juntos" e "o que faremos juntos" (VICENTE et al., 2015). Trata-se, portanto, da participação ativa do/a estudante na definição do formato da disciplina.

$\mathrm{O} / \mathrm{a}$ docente acreditar que o/a estudante sabe o que é melhor para si é algo polêmico, tendo em vista, sobretudo, a tradicional hierarquização entre o conhecimento do/a docente e do/a estudante no que diz respeito à avaliação do formato de uma aula ou uma disciplina. A proposta aqui feita é a de questionarmos aquilo que fomos levados a acreditar como sendo bom em uma aula ou disciplina, dando abertura para o/a estudante apontar aspectos positivos muito diferentes do que imaginávamos.

Em minha experiência docente na graduação em Psicologia, materializo, desde 2011, essa negociação no primeiro dia de aula, quando faço uso da ferramenta da construção do contexto conversacional (VICENTE et al., 2015). Da forma como a tenho utilizado, inicio a aula pedindo para todos se sentarem em círculo e peço que se esforcem para participar da conversa, mesmo que seja para contar sobre sua dificuldade de falar em público, no caso dos/as mais tímidos/as. Explico que esse pedido tem relação com a importância que dou para esse momento, no qual tenho a oportunidade de saber por meio deles/as mesmos/as o que eu nunca poderia saber sozinha, ou seja, saber como toda a turma poderia se sentir mais confortável durante o tempo que passaremos juntos/as. Então, faço algumas perguntas, apresentadas mais à frente neste texto, uma a uma ou juntando duas por rodada. Eles/as vão respondendo de acordo com a ordem em que estão sentados/as no círculo, o que é importante para a organização da conversa, uma vez que garante tempo de fala para todos e a oportunidade de se ouvirem sem ansiedade para falar.

Considerar a estrutura da conversa é fundamental quando pensamos em recursos dialógicos, uma vez que se entende que muitas conversas cotidianas são monológicas, ou seja, têm o império de uma única verdade, pouco espaço para a problematização de certezas, refutação, argumentação, contra-argumentação e compreensão mútua. Portanto, se queremos conversar de uma forma nova, devemos organizar a conversa de uma nova forma. Faz parte da construção do diálogo os/as estudantes ficarem em roda para a conversa inicial, o pedido de que todos/as falem e escutem, a seriedade em manter a proposta de tentar compreender as especificidades da opinião de cada um, pensar quais perguntas serão úteis, tudo isso faz parte da construção do diálogo.

A primeira pergunta que pode ser feita na construção do contexto conversacional é: "O que precisaria acontecer nesta disciplina para vocês terminarem o semestre sentindo que valeu a pena estar aqui?". Em seguida: "O que você precisaria fazer para que isso acontecesse? $\mathrm{O}$ que a docente teria de fazer?". E na sequência: "O que você pede e oferece para que essa disciplina se aproxime de suas expectativas?", e: "O que poderia ocorrer que faria você perder a vontade de estar aqui? O que poderia ser feito para que isso não acontecesse?".

Todas essas perguntas têm como objetivo um contrato de corresponsabilização docente-discentes, no qual fica claro que só é possível ser um/a bom/a professor/a com a participação da turma nesse processo e que o sucesso ou fracasso da disciplina é uma produção conjunta. Em minha experiência, os/as estudantes se engajam na tarefa, escutam uns aos outros com atenção, incluindo aqueles que são conhecidos pela turma como "perdidos/as", "desinteressados/as" ou "rebeldes", e iniciam um vínculo comigo no qual é permitido falar sobre nosso relacionamento no processo de ensino. Posiciono-me como alguém que valoriza qualquer pedido que eles/as fizerem, ouço com atenção e vou anotando na lousa, para dar 
destaque, tudo o que falarem. Eu não fico fora desse processo e também falo de meus pedidos e ofertas, que muitas vezes têm relação com minha experiência prévia sobre o que costuma dar certo e errado nas aulas. O cuidado aqui é para que não se cristalize o binômio sábio/aprendiz e que a oferta e pedidos do/a docente estejam na mesa para negociação como qualquer outro pedido e oferta da turma. Novamente, é a postura de acreditar que dessa conversa vai resultar uma fórmula eficaz para o andamento da disciplina e para o relacionamento com o/a docente.

Seguindo a proposta de construção do contexto conversacional (VICENTE et al., 2015), é importante que exista um espaço reflexivo sobre os pedidos e ofertas que foram mencionados em resposta à pergunta: "O que você pede e oferece para que essa disciplina se aproxime de suas expectativas?". Assim, ao término das rodadas de respostas e com tudo anotado na lousa, convido todos/as para avaliarem se aquilo que eles/ as ofereceram é suficiente para conquistar o que desejam. Esse é um momento de reflexão importante, pois muitas vezes os/as alunos depositam unicamente no/a docente a responsabilidade do êxito da aula e, com esse momento reflexivo, é possível conversar sobre a participação do/a aluno/a nessa construção. É significativo que esse pedido de participação do/a aluno/a não venha de uma cobrança simplesmente porque "o/a aluno tem que fazer assim", ou como fruto de discursos de julgamento moral dos/as professores/as sobre o comportamento ideal de um/a estudante, mas de um compromisso ético de negociação no qual por um lado o/a docente pede colaboração, e por outro oferece espaços constantes de escuta, disponibilidade, renegociações e feedback.

Alguns exemplos de pedidos que foram feitos pelos/as estudantes: conteúdos que façam pensar e os desafiem; articular o conteúdo da disciplina com as demais disciplinas do semestre, trazer mais casos reais e exemplos concretos para discussão em sala de aula, sair do espaço da sala de aula e se apropriar de outros espaços do campus; que docente e colegas possam ser sinceros e transparentes, que a docente dê feedback do desempenho de cada um ao longo do semestre; construção de um ambiente calmo; não ter cobrança excessiva, fazer mais discussão em pequenos grupos, ter espaço de abertura para falar com a docente, tentar conhecer mais os colegas; maior horizontalidade com a docente, estímulo para o/a estudante construir seu próprio conhecimento.

Alguns exemplos de ofertas: colaborar na construção de um ambiente confortável, ajudar a ver se o conteúdo está sendo provocador/ desafiador; interesse e participação nas aulas, dedicação, atenção, entusiasmo, esforço, presença, comprometimento, empolgação; sair da zona de conforto, tentar realizar as leituras, esforçar-se na escrita, falar mais, discutir mais, ser transparente, fazer mais perguntas; empatia à necessidade dos/as colegas, respeito, sinceridade, escuta, ajuda para pensar estratégias interessantes para as aulas.

Uma pergunta de construção de contexto conversacional que também tenho considerado muito útil para esse momento inicial das aulas, especialmente para turmas que estão desmotivadas ou decepcionadas com o ensino universitário até o momento, é: "Pense em todas as experiências significativas de aprendizagem que você teve até o momento no curso ou no ensino médio. Reflita sobre o que as tornou positivas. Agora, compartilhe com a gente de que forma essas experiências poderiam nos ajudar na construção dessa disciplina para que você consiga trazer para sala de aula o seu melhor". Essa pergunta se sustenta na premissa de que o "eu" do/a aluno não é algo estável ao longo do tempo e que, dependendo de como interagimos com ele/a, podemos ver o seu pior ou melhor, sua sabedoria, ou ignorância; enfim, é a ideia de que o/a docente participa da construção de um "bom" ou "mau" aluno/a, e que insucessos dos alunos/os devem ser pensados a partir da responsabilidade relacional e não da culpabilização individual (CAMARGO-BORGES, MISHIMA \& MCNAMEE, 2008).

Ao longo dos últimos anos, muitos foram os feedbacks oferecidos pelas turmas nas quais lecionei sobre quão positivo foi alguém ter perguntado o que eles/as achavam que era o melhor para eles/ 
as. Algumas afirmações que ouvi nesses anos: de que aquela havia sido a primeira vez que alguém fez aquelas perguntas; que era muito bom ter sua opinião valorizada, quando muitos/as docentes acabavam impondo o que deveria ser feito nas disciplinas; que se surpreenderam ao perceber que tinham boas experiências universitárias para resgatar quando achavam que tudo havia sido muito negativo em termos de aprendizagem até o momento; que as perguntas mostravam que eu tinha abertura para ouvi-los; que esse jeito de conversar e pensar a disciplina os motivava a estarem mais presentes na sala de aula e se esforçarem para cumprir o que combinamos para o semestre; que descobriram elementos novos sobre as necessidades dos/as colegas e suas razões para estarem desmotivados/as e como ajudá-los/ as. Ao longo do semestre, essa forma de iniciar a disciplina tem como efeito a maior facilidade de os/as estudantes se aproximarem de mim para renegociar aspectos das aulas sobre os quais não estão satisfeitos/as; e maior proximidade em nossas relações, de forma que posso ir entendendo como nossos combinados estão servindo ou não para uma aprendizagem efetiva.

Muitos/as docentes que entram em contato com esses recursos dialógicos pela primeira vez reagem com certa desconfiança, pois pensam que dar muita liberdade para o/a aluno leva o/a professor/a "fazer menos", abre possibilidade de o/a aluno/a enganá-lo/a e até de tomar decisões ruins para a disciplina. Posso falar apenas do que vivi até então, como professora universitária há treze anos, e aprendendo sobre diálogo em sala de aula nos últimos sete anos: mudar a forma de conversar com os/as estudantes foi mudar a forma de me entender como docente. $\mathrm{O}$ que tive até agora foram estudantes mais motivados/as, que pedem por mais tarefas, leituras e atividades - pois essas passam a fazer mais sentido e a responder a anseios, dúvidas e curiosidades do momento - estudantes mais honestos/as comigo sobre métodos avaliativos e sobre como eles/as podem ocorrer sem "ninguém passar a perna em ninguém". Não sou juíza dos/as meus/minhas alunos/as, não sou vigia de seu comportamento, não desconfio deles/as, não espero seu pior, não me defendo deles/as, eu me relaciono. E assim, dar aula ficou mais prazeroso, menos pesado, mais humano e um processo de constante aprendizagem.

Poderia aprofundar a discussão desses aspectos, mas isso não cabe neste texto. Quero apenas terminar mencionando um presente que ganhei recentemente, quando uma professora que admiro muito e que havia me contado de algumas dificuldades com relação ao ensino na graduação veio me agradecer pelos efeitos do uso dessas estratégias dialógicas com sua turma de aula. Ela me fez mais uma vez acreditar que vale a pena compartilhar essas ideias, ao dizer: "Eu não sabia como me aproximar deles, agora eu sei".

\section{Referências Bibliográficas}

BRITO, P. L. "Em Terra De Surdos-Mudos (um Estudo sobre as Condições de Produção de Textos Escolares)". Trabalhos em Linguística Aplicada, Campinas, vol. 2, 1983, pp. 149-167.

CAMARGO-BORGES. C.; MISHIMA, S. \& MCNAMEE, S. "Da Autonomia à Responsabilidade Relacional: Explorando Novas Inteligibilidades para as Práticas de Saúde". Gerais: Revista Interinstitucional de Psicologia, vol. 1, n. 1, 2008, pp. 8-19.

GERGEN, M., \& GERGEN, K. Construcionismo Social: Um Convite ao Diálogo. Rio de Janeiro: Editora Instituto NOOS, 2010.

MCNAMEE, S. \& HOSKING, D. M. Research and Social Change: A Relational Constructionist Approach. New York: Routledge, 2011.

VICENTE, A. T.; JAPUR, M.; CÉSAR, A. B. C.; RUFFINO, C. M. C. \& RUSSO, R. "The Construction of the Conversational Context of the Group". In: RASERA, E. F. Social Constructionist Perspectives on Group Work. Chagrin Falls: Taos Institute Publication, 2015, pp. 61-70. 